\title{
Analysis and Research on Island Development Model and Experience
}

\author{
Kun Zhang \\ Education Center of MTA, College of Tourism \\ Hainan Tropical Ocean University \\ Sanya, China \\ e-mail: kunzhang@ hntou.edu.cn
}

\section{Zhuang Li}

Education Center of MTA, College of Tourism Hainan Tropical Ocean University

Sanya, China

Wentao Zhang

Education Center of MTA, College of Tourism Hainan Tropical Ocean University Sanya, China

\author{
Jia Zhu* \\ College of Art \\ Hainan Tropical Ocean University \\ Sanya, China \\ * Corresponding author e-mail: zhujia1217@126.com
}

\author{
Haifeng Wang \\ College of Computer Science and Technology \\ Hainan Tropical Ocean University \\ Sanya, China \\ Chang Xu \\ Education Center of MTA, College of Tourism \\ Hainan Tropical Ocean University \\ Sanya, China
}

\begin{abstract}
In recent years, regardless of whether it is in China or abroad, the popularity of island tours has remained high, and many successful cases have emerged, which have reference significance for the recreational development of Jiajing Island. However, each island has its own particularities and cannot be generalized. It is not advisable to copy the development model of other islands in its entirety. The article summarizes some successful island development cases at home and abroad. By analyzing the characteristics of its development and development process, it hopes to play a role in the development of Jiajing Island.
\end{abstract}

Keywords-Global tourism; island development; sustainable development; successful cases

\section{INTRODUCTION}

In recent years, regardless of whether it is in China or abroad, the popularity of island tours has remained high, and many successful cases have emerged, which have reference significance for the recreational development of Jiajing Island. However, each island has its own particularities and cannot be generalized. It is not advisable to copy the development model of other islands in its entirety. The article summarizes some successful island development cases at home and abroad. By analyzing the characteristics of its development and development process, it hopes to play a role in the development of Jiajing Island [1-2].

In the China (International) Island Tourism Investment Forum held in 2018, the top ten most popular islands for tourists were published, as shown in Table I. In any quarter, Xiamen Island firmly occupied the top of the ranking list, and Wuzhizhou Island, as the only island in Hainan Province, has an important reference value for the development of Hainan's uninhabited islands [3]. This article selects Xiamen Islands and Wuzhizhou Island as the case analysis objects of domestic island recreation development. In the selection of the research object of foreign islands, the Maldives Islands with relatively high popularity are selected as the case analysis object.

TABLE I. NATIONAL POPULAR ISLAND TOUR RANKING

\begin{tabular}{|c|c|c|c|c|}
\hline Rank & First quarter & $\begin{array}{l}\text { Second } \\
\text { quarter }\end{array}$ & Third quarter & $\begin{array}{l}\text { Fourth } \\
\text { quarter }\end{array}$ \\
\hline First & Xiamen Island & $\begin{array}{c}\text { Xiamen } \\
\text { Island }\end{array}$ & Xiamen Island & $\begin{array}{c}\text { Xiamen } \\
\text { Island }\end{array}$ \\
\hline Second & $\begin{array}{l}\text { Chongming } \\
\text { Island }\end{array}$ & $\begin{array}{l}\text { Chongming } \\
\text { Island }\end{array}$ & $\begin{array}{l}\text { Chongming } \\
\text { Island }\end{array}$ & $\begin{array}{l}\text { Chongming } \\
\text { Island }\end{array}$ \\
\hline Third & Gulangyu & $\begin{array}{l}\text { Zhoushan } \\
\text { Islands }\end{array}$ & $\begin{array}{l}\text { Zhoushan } \\
\text { Islands }\end{array}$ & $\begin{array}{l}\text { Zhoushan } \\
\text { Islands }\end{array}$ \\
\hline Fourth & $\begin{array}{l}\text { Zhoushan } \\
\text { Islands }\end{array}$ & Gulangyu & Gulangyu & Gulangyu \\
\hline Fifth & Dahaodao & Dahaodao & Dahaodao & Dahaodao \\
\hline Sixth & East island & Stone island & $\begin{array}{l}\text { Temple Bird } \\
\text { Islands }\end{array}$ & East island \\
\hline Seventh & Stone island & $\begin{array}{l}\text { Changxing } \\
\text { Island }\end{array}$ & $\begin{array}{l}\text { Changxing } \\
\text { Island }\end{array}$ & $\begin{array}{l}\text { Haitan } \\
\text { Island }\end{array}$ \\
\hline Eighth & $\begin{array}{c}\text { Nanwan } \\
\text { Monkey Island }\end{array}$ & East island & Stone island & Stone island \\
\hline Ninth & $\begin{array}{l}\text { Wuzhizhou } \\
\text { Island }\end{array}$ & $\begin{array}{l}\text { Haitan } \\
\text { Island }\end{array}$ & Haitan Island & $\begin{array}{l}\text { Dongshan } \\
\text { Island }\end{array}$ \\
\hline Tenth & Haitan Island & $\begin{array}{l}\text { Temple Bird } \\
\text { Islands }\end{array}$ & $\begin{array}{l}\text { Dongshan } \\
\text { Island }\end{array}$ & $\begin{array}{c}\text { South } \\
\text { Australia }\end{array}$ \\
\hline
\end{tabular}




\section{MALDIVES ISLANDS}

The Maldives is an island country in the Indian Ocean. It consists of 1,190 coral islands, large and small, of which 220 are inhabited, and the rest are undeveloped uninhabited islands. The superior natural environment is the foundation of the Maldives tourism industry, so the Maldivian government attaches great importance to environmental protection and sustainable development of tourism. With more than 30 years of accumulation and improvement of uninhabited island development experience, the Maldives has formed a selfcontained uninhabited island development model [4-5].

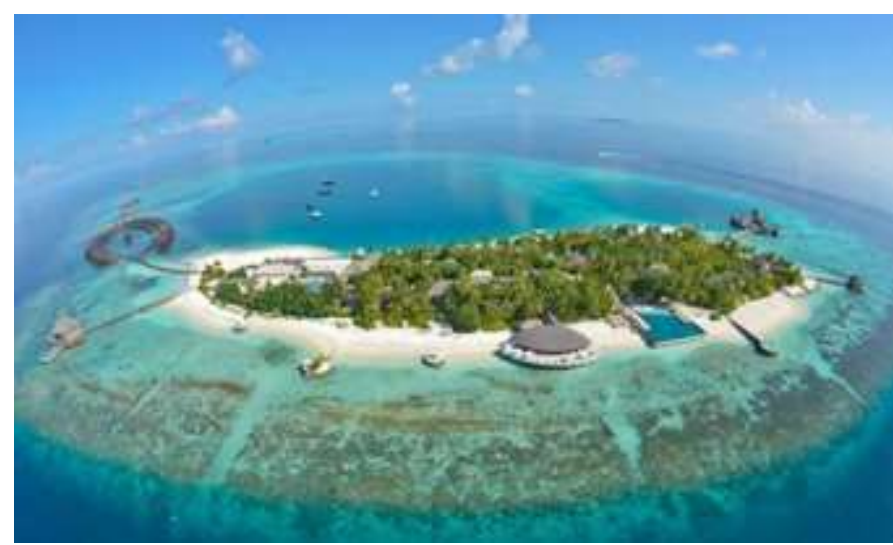

Fig. 1. Panorama of an island in Maldives

\section{A. Strict Approval Process for Island Development}

Since the Maldives government formulated the "Maldives Island Development Plan" in 1983, the Maldives has carried out the second "Decade of Island Development Plan". The Maldivian government divides the islands of the country into three regions: north, south and middle, and focuses on the needs of sustainable development. Based on the different characteristics of each island, it has adopted different political measures, development scale, development time and development methods. . It is worth mentioning that since the formulation of the plan, Maldives island development has been in accordance with the strict island development approval process, as shown in Fig. 2.

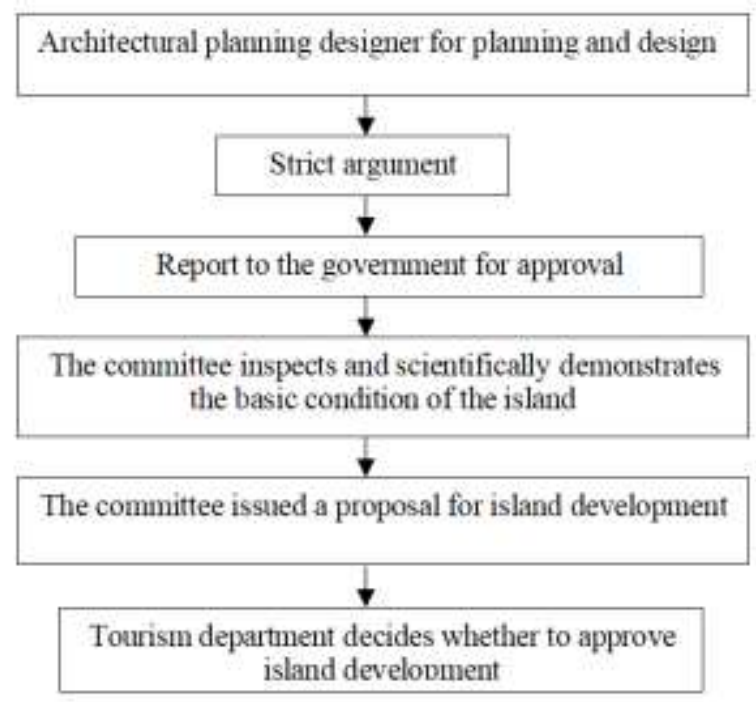

Fig. 2. Flow chart of Maldives island development approval

\section{B. "Four Ones" Model and Subjectivity of Ecological Environmental Protection Responsibility}

Since the 1980s, the maldives has been implementing the "four one" model, with remarkable results. The "four one" model refers to: an island with only one developer and operator; One resort for each island; An island develops only one style; An island should be equipped with a set of fully functional tourist service facilities. The "four one" development model can effectively avoid the island homogenization, creating a good development and competition environment for the maldives, and has been copied by many countries in the world. However, this model is difficult to imitate because of its high requirements for the overall planning and policy guarantee before development. So, up to now, the maldives is still a leader in this development model. To carry out the "four one" mode, the government should first set up a tourism construction area among the uninhabited islands. Only one resort can be built on each island. The developers should make plans according to the characteristics of the islands, and eliminate the similarity of planning schemes to highlight the unique style of each island. Secondly, the planning should be strictly approved by the tourism department of the government and carried out in accordance with the plan in the construction process. Finally, after the completion of the tourism zone, the government conducts public bidding, and the social enterprise pays the corresponding rent after the qualification examination to obtain the right to operate the island for a limited time. At the end of the lease, the government accepts an extension of the social enterprise if it invests more than a certain amount, pays a certain fee or holds a certain stake [6].

The "four one" model has many advantages. Firstly, it can avoid the homogenization of tourism resources, and secondly, it can implement the environmental protection responsibility of the island to the individual enterprises, which is conducive to the supervision of the island environment. Moreover, companies have no right to build after they lease the islands. As for the ecological carrying capacity of the islands, the tourism department of maldives has very strict indexes 
involving all aspects. It has clear and strict regulations on the height, area and spacing of all kinds of infrastructure built on the islands, and the operating enterprises have no right to rebuild or expand it. According to the regulations of the maldives tourism bureau, all activities that have an impact on the island's ecological environment can only be carried out after strict approval, and the corresponding ecological remedy should be carried out after the completion of the activities.

\section{High-end Operation Model and Exquisite Detail Management}

Many of the Maldives Islands are coral islands and reefs. Among them, there are not many islands with an area of more than 1 square kilometer that are suitable for human habitation. The ecological environment of these islands is extremely fragile. However, in recent years, the Maldives has received more than 1 million foreign tourists each year, plus more than 400,000 original residents, which has brought great ecological pressure to the fragile ecological environment of the Maldives, and its ecological carrying capacity is close to saturation. Therefore, in order to ensure or even expand the size of the Maldives tourism market, it is necessary to transform and upgrade the tourism industry, break the economic stagnation of the Maldives, and protect its fragile ecological environment. The Maldives must use its limited resources to promote stable economic growth [7-8].

The strategy adopted by the Maldives is to upgrade the level of its tourism market, develop cruise tourism, and develop high-end tourism. As cruise cruises make tourist activities mainly concentrated on ships, the ecological pressure on various islands can be reduced. In addition, convenient commuting methods, private customization, personal assistant services, numerous theme style choices, numerous meticulous design, planning and management, etc., can increase the satisfaction of tourists while increasing the consumption of tourism The level and expansion of the tourism market can also avoid the negative impact of the increase in the number of tourists on the ecological environment and provide guarantee for the sustainable development of the Maldives tourism industry [9].

\section{WUZHIZHOU ISLAND}

Wuzhizhou Island is located in Haitang Bay, Sanya City, Hainan Province. It is adjacent to Yalong Bay on the south and has the reputation of "the first bay in the world". Wuzhizhou Island has an area of 1.48 square kilometers, 1.4 kilometers long from east to west, 1.1 kilometers wide from north to south, and only 2.7 kilometers from the coastline. The entire island looks like a butterfly. Wuzhizhou Island is 30 kilometers away from Sanya City and only 38 kilometers away from Phoenix Airport. It is also close to the entrance of the expressway, with excellent location conditions and convenient transportation. Wuzhizhou Island has more than 2,000 kinds of plants and many types. It is one of the few islands in Hainan Island with rich vegetation and freshwater resources.

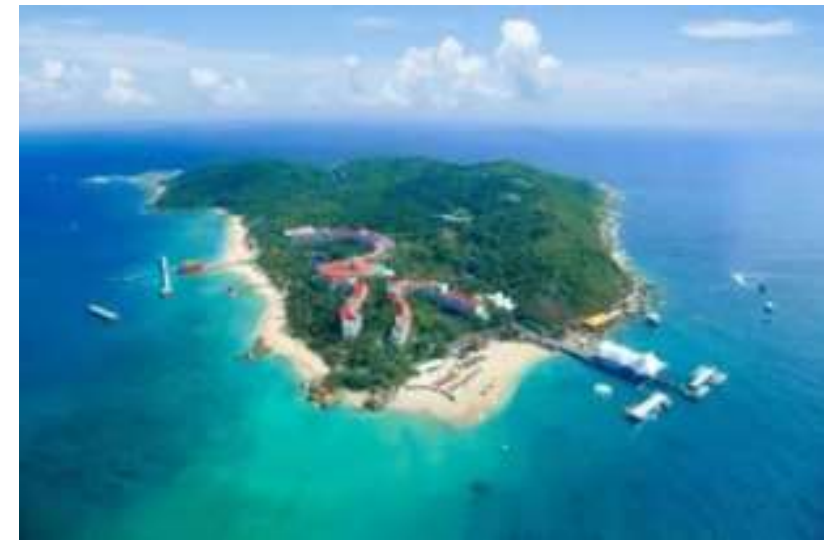

Fig. 3. Wuzhizhou Island overlooking view

Wuzhizhou Island is an uninhabited island, mainly used for leisure tourism development. The island's sea water is crystal clear, and the deepest visibility can reach 27 meters, which is called "China's first diving base". In October 2016, Wuzhizhou Island became a national 5A-level tourist attraction and is now one of the most famous tourist attractions in Hainan. The main tourism projects of Wuzhizhou Island include submarine sightseeing submarines, coral island diving, water bikes, electric boats, parasailing, motor boats, banana boats and other 20 projects. There are abundant tourist attractions on the island, and tourist infrastructure such as hotels and leisure bars have also been built [10-11]. Throughout the tourism development of Wuzhizhou Island, its development model has the following characteristics.

Finally, complete content and organizational editing before formatting. Please take note of the following items when proofreading spelling and grammar:

\section{A. Whole Lease Construction of the Whole Island}

Similar to the development model of the Maldives Islands, Wuzhizhou Island in Sanya City was leased and constructed by Hainan Seaview Paradise International Co., Ltd. as a whole. Overall leasing can make the development plan more holistic and make its development plan more comprehensive. Since the reception of tourists in 1998, Wuzhizhou Island has received tens of millions of domestic and foreign tourists. Wuzhizhou Island has a clear target market from the beginning-marine tourism in the high-end market. Therefore, the planning of Wuzhizhou Island is based on high-end and high-end travel customers, such as star-rated hotels and entertainment performances, deep diving experience, etc. Whether it is project development or infrastructure construction, it fully meets the goals [12-13].

\section{B. Marine Pasture Power Comes First}

Open the official website of Wuzhizhou Island, and the column of "Ocean Ranch" suddenly catches your eye. In recent years, tourism development, overfishing, and pollution emissions have caused the lack of offshore fishery resources, resulting in an unbalanced marine ecosystem. The construction of "ocean pastures" is an important measure to focus on solving this problem. High-level development must be escorted by 
high-level environmental protection programs. The marine pasture of Wuzhizhou Island is China's first large-scale tropical marine pasture. The construction of Wuzhizhou Island Tropical Marine Ranch has promoted the integration of fishing and tourism, injecting sustainable marine ecological elements into the tourism upgrade of Wuzhizhou Island, and providing valuable experience for the development of other islands [14].

\section{Excellent Publicity Channel}

The movie "Private Customization" has made many audiences understand the existence of Wuzhizhou Island. Wuzhizhou Island is well known by the tourists for its beautiful natural environment shown in the movie, and this opportunity has opened up the popularity for Wuzhizhou. The establishment of the brand image of Zhizhou Island provides great help. At the same time, Wuzhizhou Island also attaches great importance to the placement of advertisements. The official website is well-made and can allow visitors to access the information of Wuzhizhou Island through various channels, and can also find the corresponding travel strategy, which is invisible It also adds a bit of appeal to Wuzhizhou Island.

\section{Unique Features of Scenic Spots}

After the Wuzhizhou Island Scenic Area was built, many unique play projects were launched. From a garden-style immersive experience to a visually stunning beach setting, from a deep diving experience to a variety of exciting water projects. With these special projects, Wuzhizhou Island opened its popularity at the time and gained a good reputation. After this, Wuzhizhou Island keeps pace with the times and continuously develops new entertainment projects to bring various new experiences to tourists. For example, during the Spring Festival in 2017, Wuzhizhou Island invited the Cirque du Soleil, known as the "National Treasure of Canada", to jointly launch a wonderful performance. During the Spring Festival holiday alone, it received a total of 90,400 domestic and foreign tourists, an increase of $15.78 \%$ year-on-year. The increase in exposure in the domestic market is a win-win situation for all three parties. In addition, Wuzhizhou Island has also launched on-shore sightseeing tours and extreme challenge projects, as well as high-end services such as private guides and private customizations, providing more different options for different tourists [15].

\section{XIAMEN "ChUAN ISLAND TOUR"}

Although Xiamen Island and Gulangyu are the most wellknown tourist attractions in Xiamen, in addition to Xiamen Island and Gulangyu, there are 17 large and small uninhabited islands with an area of more than 500 square meters. For example, Crocodile Island, Datuyu Island, Xiaotuyu Island, etc. are distributed in 300 square kilometers of waters near Xiamen, accounting for more than $80 \%$ of the total number of islands in Xiamen waters. These islands are a natural protective barrier for the coastline of Xiamen and an indispensable part of Xiamen's construction of an eco-port scenic tourist city. In the early development process, people did not pay attention to the protection of the ecological environment. Large construction on the island, random development of reefs, and even aquaculture on the island seriously damaged the ecological balance of the island, resulting in the fragile ecosystem of these uninhabited islands., Lack of fresh water resources, poor environmental conditions, etc. Therefore, in order to successfully build Xiamen's eco-port scenic tourism city and protect the island's ecological environment, the Xiamen Municipal Government has launched a "string island tour" development plan, which has the following two characteristics in the development process.

\section{A. The Government has Introduced Policies to Protect Development}

Xiamen City adheres to the principle of protection first, harmonious symbiosis for the development of islands, and protects and develops non-resident islands through legislation, preparation of plans, and continuous improvement of bills and plans. In 2018, the Xiamen Municipal Oceanic and Fishery Department cleaned up uninhabited islands and demolished and cleaned illegal buildings. At the same time, experts and scholars from Xiamen University and the Three Institutes of Oceanography were jointly investigated and planned to protect the island by closing the island, and repairing the damaged ecological environment by artificial restoration. Formulate a plan to "repair two islands a year" and gradually carry out ecological restoration of islands with damaged ecological environment.

\section{B. One island, One Policy, Multi-wire Serial}

Under the leadership of the Xiamen Municipal Government, it has created a "string island tour" project that includes 8 uninhabited islands, and plans to introduce an investment of 4.1 billion yuan, as shown in Figure 3.4. The eight islands have their own themes and positioning, "one island, one policy". The theme of Huoshao Island, Datu Island and Zhuyu Island is tourism and entertainment, the theme of Crocodile Island and Tuyu Island is leisure vacation, the theme of Jiyu Island and Lantau Island is leisure and experience, and the theme of Dalipu Island is science education. In the plan of Xiamen Municipal Government, it is necessary to display the natural scenery of mangroves and other natural scenery on Crocodile Island; make Baozhu Island, Tuyu Island and Dalipu Island into tourist islands, and restore the original buildings and landscapes on the island, and increase the human landscape and geographical landscape, to show visitors the historical and cultural features of these islands [16]

It is not difficult to see from the case of Xiamen "Tour Island Tour" that the government's decision plays a crucial role in the development of Xiamen's uninhabited islands. From the overall planning, to restoration and governance, to the final operation of each node setting, the Xiamen Municipal Government has played an indispensable role. When the ecological environment of Xiamen's uninhabited islands is completely restored, its beautiful scenery will appear again, adding to the scale of Xiamen's "string island tour". The development of Xiamen City on uninhabited islands has already taken the lead nationwide, and its development concept and development model are of reference significance. 


\section{CONCLUSION}

The most favored development model of the Maldives Islands is "one island, one scene". There is no single competition between the islands and the tourist areas. Each island has a different style, each island has a unique attraction, so that there is no homogeneous competition between each island, and each island has its own target population, which is largely avoided the appearance of "more wolves and less meat" is conducive to the formation of a good market competition scene. In addition, the Maldives has adopted a different strategy in maintaining the sustainable development of the island. Since the ecological carrying capacity of each island is limited, controlling the number of tourists is an inevitable choice. The approach taken by the Maldives is to carry out projects such as cruise routes, shifting the venues for tourists, and while controlling the number of tourists on the island, it can also open up the market for high-end tourism. Not only can the number of tourists be guaranteed, but it can also increase Maldives' tourism revenue. Taking the offensive as the defense, and carrying out new projects to protect the ecological environment of the island, this is very worth learning.

Wuzhizhou Island is an island with the most similar natural conditions to Jiajing Island. However, Jiajing Island is difficult to compare with Wuzhizhou Island in terms of its own resource endowments and location conditions. Therefore, following the model of Wuzhizhou Island, it is not the best choice for Jiajing Island, but the development experience of Wuzhizhou Island It can still provide some inspiration for the recreational development of Jiajing Island. First, Wuzhizhou Island belongs to the overall leasing development, so there is a stricter management system in the management of scenic spots, and there is a high degree of uniformity in the development of tourism products and projects, so that tourists will only feel that tourism products are very good. There will be no sense of violation. Second, Wuzhizhou Island's market positioning is very precise. Locking in the mid-to-high-end tourism market is not only conducive to Wuzhizhou Island 's image positioning, but also speeding up the opening of Wuzhizhou Island 's market awareness and ensuring the economic benefits of Wuzhizhou Island. Prevent the number of tourists from going online beyond the carrying capacity of the scenic spot, and ensure the service level of the scenic spot, thereby achieving sustainable tourism. Third, the construction of Wuzhizhou Island's tropical marine pastures is undoubtedly an innovative and important measure in line with the principle of sustainable development. This coincides with the basic principle of sustainable development in the recreational development of Jiajing Island. In terms of recreational development, it has important reference significance. Fourth, Wuzhizhou Island attaches great importance to market reputation and has made great efforts in marketing. Under the same conditions, tourists are more inclined to choose to travel to Wuzhizhou Island, and its means of publicity and marketing is well worth learning.

Xiamen "Tour Island Tour" is a typical case of government overall planning. The government took the lead and carried out in an orderly manner under the scientific and overall planning. The experience that the development process can provide for Jiajing Island lies in the proper intervention of the government and protection of the ecological environment during the development process. These are precisely the elements that need to be paid attention to during the recreational development of Jajing Island.

\section{ACKNOWLEDGMENT}

This research was financially supported by the Sanya Planning Projects of Philosophy and Social Sciences (No.SYSK2019-07); 2019 Education and Teaching Reform Project of Hainan Tropical Ocean University (No.RHYJG2019-17).

\section{REFERENCES}

[1] H.H. Yan, "Research on the Ecological Environment Evolution and Evaluation of Wuzhizhou Island Marine Ranch Tourism Area in Sanya" CN: Hainan University, 2017.(In Chinese)

[2] H. Hong, Y.X. Hu, S. Hu, "Development Status and Innovation Development of Unmanned Island in Zhoushan," China Population, Resources and Environment, No.S1, 2010, PP. 439-442.(In Chinese)

[3] K. Zhang, C. Shen, H.W. Li, etc., "Direction of Arrival Estimation and Robust Adaptive Beamforming With Unfolded Augmented Coprime Array," IEEE Access, Vol.8, 2020, pp. 22314-22323.

[4] Y.G. Liu, "Liaoning Island Economy and Development and Utilization of Unmanned Island (Part 2)," Liaoning Economy, No.02, 2013, pp. 7579. (In Chinese)

[5] C. Shen, C.X. Wang, K. Zhang, etc., "A Time Difference of Arrival/Angle of Arrival Fusion Algorithm with Steepest Descent Algorithm for Indoor Non-Line-of-Sight Locationing," International Journal of Distributed Sensor Networks, Vol.15, No.6, 2019, pp.1-8.

[6] K. Zhang, C. Shen, Q. Gao, etc.,"Precise Positioning System of Ship Interior Based on UBW Ultra Wideband Technology," Journal of Coastal Research, Vol.83, No.sp1, 2018, pp. 908-912.

[7] Q.B. Wang, "The development, protection and management of unmanned islands in South Korea," Ocean Development and Management, No.10, 2015, pp. 30-34. (In Chinese)

[8] K. Zhang, C. Shen, H.F. Wang, etc., "Design Of Ship Medical Rescue Communication System Based On Mimo Precise Positioning," Indian Journal Of Pharmaceutical Sciences, Vol.80, No.S1, 2018, pp. 42-43.

[9] M. Ren, J. Dai, "Suitable Spatial Planning and Design in Tourism Development of Unmanned Island," Economic Research Guide, No.26, 2017, pp. 121-122. (In Chinese)

[10] Y.S. Miao, "Zhejiang Province Research on the Development and Management of Unmanned Islands," Marine Information, No.04, 1999 , pp. 23. (In Chinese)

[11] K. Zhang, C. Shen, H.W. Li, etc., "Design of Robot System for Hospital Infection Prevention and Control Based on UWB Technology," Basic \& Clinical Pharmacology \& Toxicology, Vol.126, 2020, pp. 68-69.

[12] Y.N. Yang,’Dynamic monitoring of the development and utilization of uninhabited islands in Liaoning based on remote sensing," Technology Innovation and Application, No.20, 2019, pp. 65-66.(In Chinese)

[13] W. Fang,"Island, the Pearl Pnlaid on the Blue Land," Ocean and Fishery, No.01, 2019, pp. 4-5.(In Chinese)

[14] K. Zhang, C. Shen, Q. Zhou, etc. "A Combined GPS UWB and MARG Locationing Algorithm for Indoor and Outdoor Mixed Scenario, "Cluster Computing - The Journal of Networks Software Tools and Applications, Vol.22, No.SI3, 2019, pp.5965-5974

[15] J. Liao,"Zhuhai Delta Island, Public Welfare Development of Ecological Tourism," Ocean and Fishery, No.01, 2019, pp. 20-23.(In Chinese)

[16] K. Zhang, C. Shen, H.F. Wang, etc. "Cluster Computing Data Mining Based on Massive Intrusion Interference Constraints in Hybrid Networks," Cluster Computing - The Journal of Networks Software Tools and Applications, Vol.22, No.SI3, 2019, pp.7481-7489. 